\title{
Face-to-face Tutorial : Students' Satisfaction Analysis
}

\author{
Adji, S.S. ${ }^{1}$, Suciati $^{2}$ \\ ${ }^{1,2}$ Faculty of Education and Teacher Training, Indonesia Open University
}

Corresponding email: sandrasukmaning@gmail.com

\begin{abstract}
One of the characteristics of distance learning students study away from educational organization, and Institution should provide learning assistance to its students in academic services which is implemented with tutor guidance. The students will feel satisfied when their learning had fulfilled their needs. This study aims to analyse the students' level of satisfaction and expectations in the tutorial activities of some subjects provided in Post Graduate Program. Indicator used in achieving the satisfaction are the passage of communication among students, the interaction in the class face to face tutorial and the ability of tutors in guiding student learning. The data obtained through questionnaires to students from 10 region. The sample of this study were 260 from 1198 students, and populations come from 3 magister program. 30 students use as pilot project through 18 items questionnaire test. By using "product moment" correlation technique, obtained each items pertained valid. The result showed in average, the students gave satisfaction assessment above 3.25 of the scale 4 . The items were students' satisfaction on the tutorial environments; students' satisfaction on the communication intertwined with the face-to-face tutors; students' satisfaction on the tutors' capability in transferring the science substance; and satisfaction to the interaction occurred in face-to-face tutorials and the tutor's role in tutorial activities. There was a relationship between students' satisfaction in following face-to-face tutorial with the final semester exam, Master of Basic Education $\mathrm{R}^{2}=$ 0,027, Master of Public Administration $\mathrm{R}^{2}=0,01$ and Master of Management equal to $R^{2}=0,015$.
\end{abstract}

Keywords: Student satisfaction; Face-to-face tutorial; Relationship level

DOI: http://dx.doi.org/10.20961/ijpte.v3i1.26210 


\section{INTRODUCTION}

Distance learning students lack of social relationships and feel loneliness (Weiss, 1973). One of the reasons that lifts the spirit of the students which can be seen in how they would perform and feel satisfied towards the course they take is the presence of other people, or in other word Social Presence (Garrison et al, 2000; Garrison \& Arbaugh, 2007). The researches that have been done in Open University (Universitas Terbuka) as of now mostly revolved around how effective the distance learning courses in providing the study, the communication of the tutor and their student as well as how the students communicate among themselves, and the students' satisfaction in their study. Research on learning assistance services have been done, both face-to-face tutorials and online tutorials. Adji.S.S and Suroyo (2016) examined that the students' satisfaction in following the online tutorial of the Basic Education in Master's program in UT, the result showed students were satisfied with an average score above 3.5 of the scale 4 in online tutorial.

The Post-Graduate Program at the Open University provides face-to-face tutorials as one of its learning services. In addition to face-to-face tutorials, its also provides learning assistance services in the form of online tutorials. Both of the learning assistance services which are mutually synergized and integrated, must be followed by students. Although it is not fully blended learning, the use of both patterns of learning aid has referred to blended learning. The learning cycle at the program for one semester is basically a self-study, but however the students are given learning assistance in the form of face-to-face tutorials and online tutorials that are assembled in a series of lessons. The series of learning activities are described as follows.



Figure 1. Learning Activities at UT Magister Program Source : Katalog UT

According to Smyth, Houghtin, Cooney \& Casey (2012) several benefits and challenges of blended learning, students appreciated the accessibility and flexibility that they thought characterized blended learning. Result study of Huang, Qiang (2016) explained that the face to face learning and on line learning had mixed well within the blended course as helpful and complementary to each other by making each other more interesting and more effective. 


\section{METHOD}

The research was conducted at UT Central and at UT regions. The population was all students of the face-to-face tutorial for courses offered by 3 program, students of Master Program of Public Administration, Master of Management and Master of Basic Education. The population were 1198 students, and the sample were 260, Indicator used in achieving the satisfaction are the passage of communication among students, the interaction in the class face to face tutorial and the ability of tutors in guiding student learning. The data obtained through questionnaires to students from 10 region. 30 students use as pilot project through 18 items questionnaire test. By using "product moment" correlation technique, obtained each items pertained valid. The questionnaires use scale of 4 . Value $4=$ very good $/$ very high, value $3=\operatorname{good} /$ high, value $2=$ medium, value $1=$ less good $/$ less high. The higher score indicates the higher satisfaction level. then the lowest score was 260 and the highest was 1040. The difference between the two scores was divided by 3 and the numbers obtained was used as the range or interval in determining the categories i.e. scores above 780 were classified as 'Good', scores 520 up to 780 were classified as 'Medium' and the scores below 520 were classified as 'Less'. All data obtained was analyzed descriptively quantitative.

\section{RESULTS AND DISCUSSION}

The value of reality and students' expectations on the statement point of :

\section{Communication in learning}

The communication between the students and the tutor becomes necessary in the learning activities (Rawat,2016; Muste, D, 2016.). Communication also occurs in the tutorial class, as well as through short message service (sms) and email. Students's assessments to the communication with tutors on tutorial face-to-face activities as shown in Figure 2

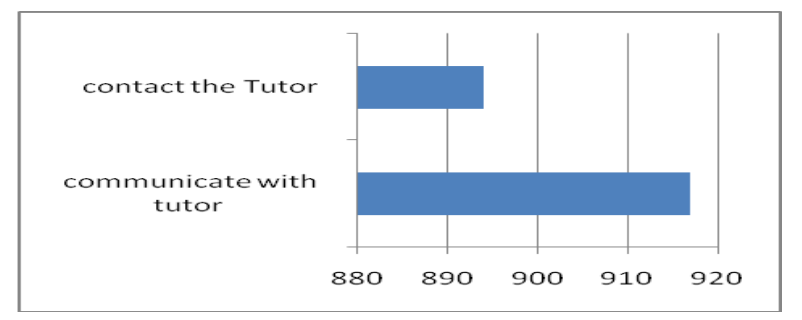

Figure 2. Student's opinion on the communication built between students and tutors

Through Figure 2, using a scale of 4 , it can be explained that students tended not to find difficulty in communicating $(\mathrm{X}=3.54)$, and contacting face-to-face tutor $(X=3.37)$. Scores obtained indicated the numbers of 917 and 894 , therefore it can be explained that the communication had been going well, tutors were willing to be contacted hence the students could tell the learning problem to their tutor. 


\section{Student satisfaction with the tutor's capability to transfer the substance of his knowledge}

According to Afzaal, Ali, and Ahmad, I. (2011) the majority of the students satisfaction regarding student-instructor interaction, instructor's performance and course evaluation. In the study, the students assessed the face-to-face tutors were well-mastered the substance material they delivered. $(X=3.59)$, and well-explained the scope of material to be discussed in each meeting ( $\mathrm{X}=$ 3.56) which the scores obtained were 931 and 928 . Through the Figure 3, it can be explained that the students had fulfilled their needs as the tutor had been able to answer or explain the being studied topic material during the tutorial.

The tutor provide instructions, guide the students to learn the materials, help to analysis and synthesize the course material, organize students collaboration and interaction (Krasnova, T. And Demeshko, M.. 2015). Students gave high assessments on the mastered face-to-face tutors in answering student questions $(\mathrm{X}=3.63)$ and scored 944 . In addition the tutors were able to answer questions as well as explain the relevance /importance of topic / subtopic tutorials in the scientific context $(X=3,52)$ and scored 912 .

The mastery of the material shown by the tutor is thought due to the tutors' competence in the field, and attempts to add examples of learned concepts and their applications in the work world. In addition, in using the subject matter book, the tutor used and directed to search various sources of literatures as references. Thus the students gain a lot of knowledge and insight about the subject they were studying. The searching various sources of literatures could increase someone's knowledge (RAFT, 2013).

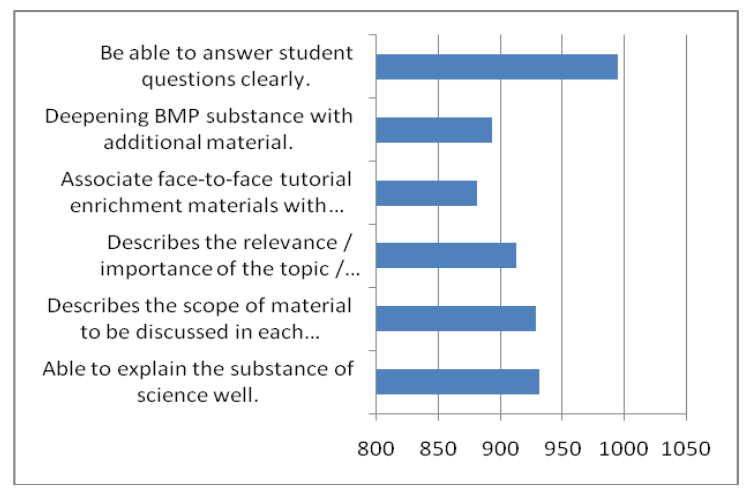

Figure 3. Student opinion on tutor mastery in tutorial substance

Institution designed the discussion in the face-to-face tutorials as well as online tutorials. Students assumed that there was a link between the material presented in the face-to-face tutorial with those in the online tutorial and the face-to-face tutors could relate the materials to one complete discussion ( $\mathrm{X}=$ 3.41) and score 881. Even the tutors were able to give material enrichment to help students understand the substance in the Basic Matter Book $(X=3.43)$, and score 893. 


\section{Interactions that occurred in the activities of face-to-face tutorial}

Tutors used diverse tutorial models such as presentations, group work, and frequently asked questions $(X=3.35)$ and scored 869 . This was seen by students as the main interest/attraction of the tutorials. The students gave the score $(\mathrm{X}=3.44)$ and the 893 score on the interaction constructed by the faceto-face tutors to the students, this was indicated by the tutors' invitation to ask and answer any questions happened in class $(X=3.63) 945$, as shown in Figure 4.

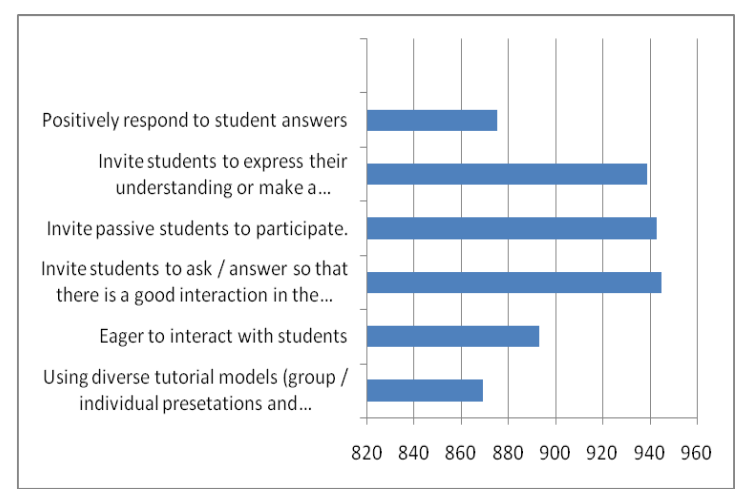

Figure 4. Student's opinion on the interaction that occurred during face-to-face tutorials

Besides inviting students to ask questions or answer questions the tutor also asked passive students to participate in the tutorial $(\mathrm{X}=3.62)$, and scored 943. The such activities included asking students to express their understanding or doing presentations in front of the class $(X=3.61)$ and scored 939. The tutor gave a positive response to the student's answer $(X=3.36)$, scored 875

\section{The Tutor Role in Giving Guidance to the students}

The students gave high marks on the tutors' role in reminding students to prepare questions for discussion at the next face-to-face tutorial $(X=3.43)$, scored 892 and reminding students to read the module section (in the Basic Matter Book) that would be discussed at the next face-to-face tutorial meeting $(X=3,46)$ and scored 902. Students gave good responses $(X=3,34)$ and scored 870 in practicing questions given by the tutor in case study form. The sums in the form of a case study is useful to train students to be able to arise high-level thinking i.e. doing analysis, synthesis, drawing conclusions and making or proposing ideas based on the their analysis. 


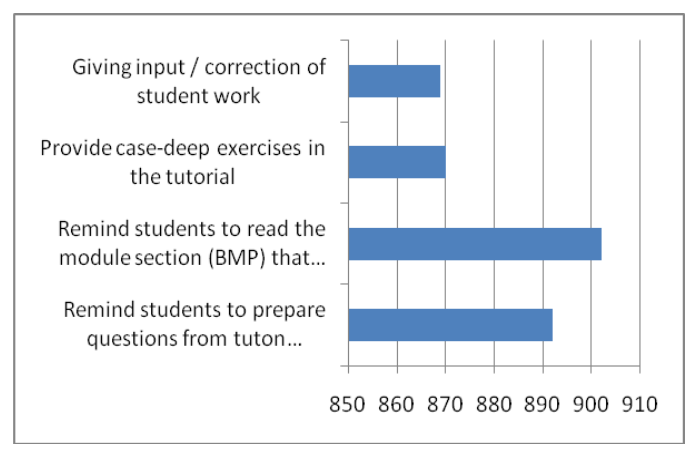

Figure 5. Student's opinion in Giving Guidance to the students

From Figure 5 it can be explained that the students gave good ratings ( $\mathrm{X}=$ 3,34 ) and scored 869 to the tutor for giving input of students' work based on the exercises and the tasks given during the tutorial.

\section{The Comparison of Students' Satisfaction and Interest}

Comparing between students' satisfaction scores and the students' interest from the indicators of difficulty in communicating and contacting face-to-face tutors, the difference value was not greater than 0.1, as shown in Figure 6.

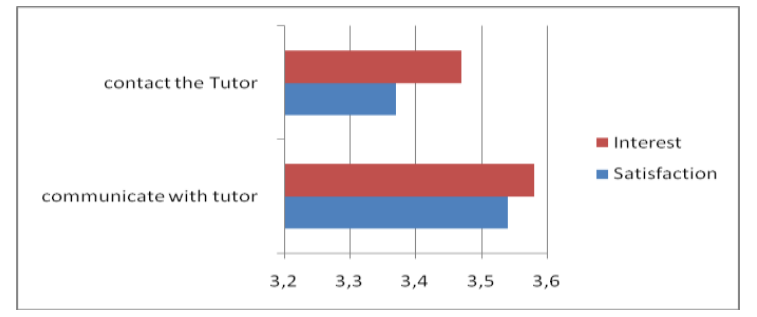

Figure 6. Differences between students' satisfaction and students' interests on the communication built between students and tutors

Nevertheless, even though the students had rated satisfaction value well, with the average value above 3.35 but the students considered that both of the statements were still important. Students tended to give high value to the students interests in the indicators that described the mastery of face-to-face tutors on the substance of the material presented. Furthermore, to compare the value of students' satisfaction with the students' interest from each indicator, the value of students' interest tended to obtain higher scores than the value of students' satisfaction. However, although the rate of students' satisfaction was quite good i.e. the average was above 3.40 , comparing with tutors' mastery and competence in delivering the tutorial substances/materials, but the students considered it was still necessary to be improved. 


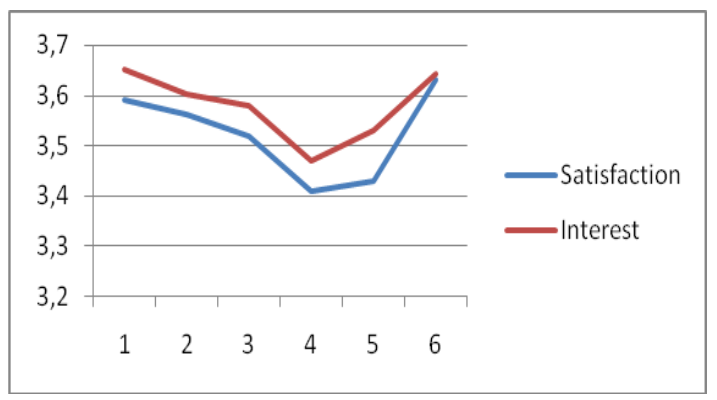

Figure 7. The differences between the value of students' satisfaction and interests on tutors' mastery of the substances/material

The biggest difference in student ratings was shown in the indicator of additional material to deepen the subject matter book substance by 0.1 while the other indicator showed the difference number below it, as shown in Figure 7. This illustrates that the students had not yet needed any other additional substances than that the substances contained in the subjects matter book. A somewhat different of students' assessment was shown in the interaction that occurred during a face-to-face tutorial, as shown in Figure 8

Through Figure 8 it can be explained that there were various students' assessments based on the value of satisfaction and interest from the indicators: building interaction in classroom learning. Comparing between the value of students' satisfaction and the students' interest in each indicator assessed of the interaction that occurred during face-to-face tutorials. This indicated that although these indicators had been well rated with an average score above 3.4 but students assumed that these components should still be maintained and considered since they were required by the students.

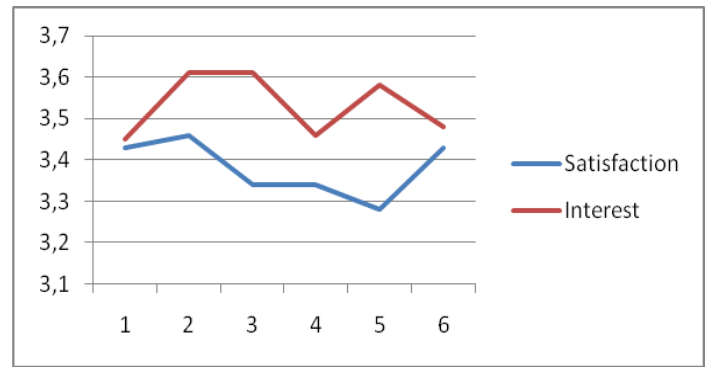

Figure 8. The differences between the value of students' satisfaction and interests on the interaction that occurred during face-to-face tutorials

The students considered that the provision of deepening training on the lecher is lower than its importance. Through this information it is suspected that students were less likely to have additional exercises about the cases bundle. While the student judged it was an important matter for the indicator about the input and response of the tutor to the results of his work as shown in Figure 9. 


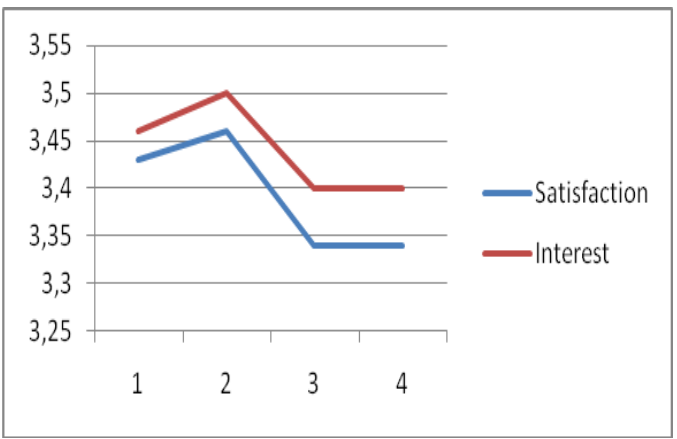

Figure 9. The difference between the value of satisfaction and the interest of the student toward the response given by the tutor during the tutorial

Through Figure 9, it can be explained that although the student rated more highly to students' satisfaction i.e. above 3.25 than the tutor's response to student work but the response component of the tutor were still required by the students. Students need feedback on their learning outcomes (Adji, S.S and Sunarsih, 2017 ; Berge, 1999).

Furthermore, the gap value of the whole item statement about the satisfaction of interest as shown in Figure 10.

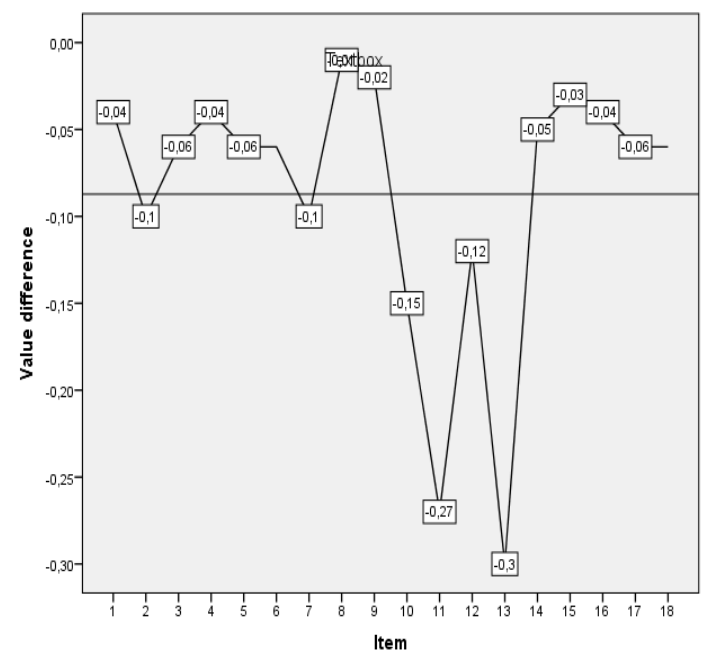

Figure 10. Distribution of the difference value of each item

Through Figure 10, it can be explained that the items of the statement about the contact the tutor, deepening the subject matter book, substance with additional material, eager to interact with students, invite students to ask / answer, invite passive students to participate, and positively respond to student answers got below average value. This indicated that the items of the statements need special attention to improve the learning program especially in face to face tutorials. 


\section{The influence of tutorial on student learning outcomes of Master Program of Basic Education of Post Graduate Program}

Based on the results of the analysis, it shows the correlation between the participation of students in the face to face tutorial with the final exam of the semester, the value for three study program are Master of Basic Education program $\left(R^{2}=0.027\right)$, the Master of Public Administration $\left(R^{2}=0.01\right)$ and the Master of Management program $\left(\mathrm{R}^{2}=0.015\right)$. The presence of face-to-face tutorials is seen to be very helpful for students in understanding the subject matter offered. The figures show the relationship of giving face-to-face tutorials to student learning outcomes in the final exam of the semester, but has a relatively low level of relationships.

\section{CONCLUSION}

Separation between students with tutors / lecturers on distance education can be bridged with the learning assistance such as tutorials both online and face to face. Considering that Distance Education students are in a location far from the main teacher. The existence of tutorials can be used to reduce the loneliness and solitude of students and it also can be use to build interpersonal relationships with other friends. This study is in line with Dillon, Gunawardena and Parker (1992) which reported the communication between the students can make them feel less lonely, while Angelaki and Mavroidis (2013) described the communication between the tutor and their student as well as between the students themselves are able to reduce the loneliness and solitude experienced by students. Smyth et.al. (2012) describe that interactive activities in face to face learning help student to engange more with their peers in class and develop close association with each other that may develop a strong learning. In contrast, Moore, G.E., Warner, W.J and Jones, D.W.W. (2016) in their study at graduate sstudents in agricultural and extension classes, explaine that a distance do not desire student-to-student interaction in their classes, some students who tended to be positive about having student-to-student interaction, there were some who didn't. Students are more concerned with the course content then they are with building or participating in a classroom community.

The study also show material being studied requires a reasoning and analysis then the providing tutorial is supposedly helpful to the students in achieving the expected learning outcomes. Achievement of this ability can be obtained by the interaction between the tutor to students and students to students through learning models of question and answer and discussion in the classroom. The interaction that occurs in face to face tutorial activities is not only between the tutor to the students or the students to students, but in the interaction the tutor uses the material/content as a medium between them, that is by inviting students to browse the various literatures as enrichment materials.

Although the existence of tutorials can motivate student learning but they have not given a big influence on students' learning outcomes stated in the final exam 
of the semester. Therefore, a reversal from the tutor on the students' work is really expected to train the students to solve the problems of some matters and cases given in the tutorial material to improve the learning outcomes.

\section{REFERENCES}

Afzaal, A.A. and Isra,A. (2011). Key factors for determining students' satisfaction in distance learning courses: A study of Allama Iqbal Open University. Contemporary Educational Technology, 2(2): 118-134.

Adji.S.S and Suroyo (2017), Student Participation in Discussion Forum in Online Tutorial (UT's experience), the 31 Annual Conference of the Asian Association of Open University, AAOU 2017., Yogyakarta.

Adji,S.S. and Sunarsih, (2017). Students' Satisfaction in Online Tutorial, Advances in Social Science, Education and Humanities Research (ASSEHR), volume 149. 2nd International Conference on Education, Science, and Technology (ICEST 2017). Copyright@2017, the Authors. Published by Atlantis Press.

Angelaki, C.; Mavroidis, I. (2013). Communication and Social Presence: The Impact on Adult Learners' Emotions in Distance Learning. In European Journal of Open, Distance and eLearning, 16(1), (pp.78-93). http://www.eurodl.org/materials/contrib/2013/Angelaki_Mavroidis.pdf

Berge, Z. 1999. Interaction in post-secondary Web-based learning. Educational Techonogy, 39 (1): 5-11

Dillon, C.L.; Gunawardena, C.N.; Parker, R. (1992). Learner support: critical link in distance education. In Distance Education, 13(1).

Garrison, D.R.; Anderson, T.; Archer, W. (2000). Critical Inquiry in a text based environment: Computer conferencing in higher education. In The Higher Education, 2((2/3), (pp.87-105).

Garrison, D.R.; Arbaugh, J.B. (2007). Researching the community of inquiry framwork: Review, issues \& future directions. In The Higher Education, 10((3), (pp.157-172).

Huang, Qiang (2016)., Learners' Perceptions of Blended Learning and the Role and Interaction of f2f and Online Learning., ORTESOL Journal, vol. 33.(pp14-31).

Krasnova, T tatiana and Demeshko, Maria (2015). Tutor-mediated Support in Blended Learning., International Conference on Research Paradigms Transformation in Social Sciences 2014. National Research Tomsk Polytechnic, University Tomsk Rusia. Procedia : Social and Behavioral Sciences 166(2015) 404-408. Available online at www.science direct.com

Markova, Tatiana; Glazkova, Irina; and Zaborova, Elena., (2016). Quality Issues of Online Distance Learning. 7th International Conference on Intercultural Education "Education, Health and ICT for a Transcultural World", EDUHEM, 15-17 June 2016, Almeria, Spain. Procedia: Social and Behavioral Sciences. Online at www.sciencedirect.com

Moore, G.E., Warner, W.J and Jones, D.W.W. (2016). Student-to-student Interaction in Distance Education Classes: What Do Graduate Students 
Want?. Journal of Agridultural Education. 57(2), 1-13. Doi: 105032/Jae.2016.02001

Muste, Delia. (2016). The Role of Communication Skills in Teaching Process, The Europian Proceedings of Social \& Behavioural Sciences EpSBS, eiSSN 2357-1330, p. 430-434., Future Academy.

RAFT. (2013). Resource Area For Teaching., Bridging the Engagement Gap with Hands - On Teaching, http://www.raft.net/public/pdfs/case-for-hands-onlearning.pdf

Rawat, Deepti. (2016). An International Peer Reviewed \& Referred, Scholarly Reseach Journal for Interdiciplinary Studies., ISSN 2278-8808, vol 4/26., p. 3058-3063

Smyth,S, Houghtin,C, Cooney,A.. \& Casey, D. (2012). Students' experiences of blended learning across a range of postgraduate programmes. Nurse Education Today, 32(4): 460-468.

Suarman, Z.A. and Yasin, R.M. (2013). The Quality of Teaching and Learning towards the Satisfaction among the University Students, Asian Social Science, Vol. 9, No. 12., ISSN 1911-2017 E-ISSN 1911-2025, Canadian Center of Science and Education Publishers.

Universitas Terbuka. (2016). Katalog program pascasarjana Universitas Terbuka 2016. Tangerang Selatan: Universitas Terbuka.

Weiss, R.S. (1973). Loneliness. The experience of emotional and social isolation. Cambridge, M.A: The MIT Press. 
